\title{
ENVELHECER ADOECENDO: \\ RELATOS DE PACIENTES IDOSOS INTERNADOS NO HOSPITAL UNIVERSITÁRIO JÚLIO MULLER, CUIABÁ, MT
}

\author{
Kamilla Braz Campos ${ }^{1}$ \\ Ana Rafaela Pecora²
}

resumo

Este estudo objetivou levantar e analisar as representações sociais que idosos internados no Hospital Universitário Júlio Muller, em Cuiabá, MT, constroem acerca do processo de envelhecer adoecendo. Foram realizadas entrevistas semiestruturadas com 15 idosos hospitalizados em decorrência de comprometimentos cardiovasculares. O material discursivo foi organizado e processado pelo software ALCESTE. A análise dos conteúdos permitiu verificar que as representações elaboradas e compartilhadas pelas pessoas inquiridas no estudo englobam as perdas e dificuldades relacionadas ao envelhecimento marcado pelo adoecimento, e, também, o mecanismo de enfrentamento desse processo. Esse mecanismo é construído pela força

\footnotetext{
1 Graduada em Psicologia. Especialista em Saúde do Adulto e do Idoso com ênfase em Atenção Cardiovasccular. Mestranda no Programa de Pós-Graduação em Saúde Coletiva da Universidade Federal de Mato Grosso (UFMT). E-mail: kamilla.braz@hotmail.com

2 Graduada em Psicologia. Doutora em Psicologia Social. Professora Adjunta da Universidade Federal de Mato Grosso (UFMT) vinculada ao Departamento de Psicologia. E-mail: arpecora@terra.com.br
} 
interior alcançada através de experiências vivenciadas, o apoio familiar, o cuidado recebido e o acesso aos serviços de saúde.

palavras-chave

Envelhecer Adoecendo. Pacientes Idosos. Psicologia da Saúde. Representações Sociais.

\section{Introdução}

O fenômeno mundial do aumento progressivo da população idosa constitui uma conquista da humanidade, mas também implica novas demandas sociais e econômicas, sendo, destarte, um dos maiores desafios para a saúde pública (VERAS, 2009). Apesar de estudos recentes abordarem as perdas e ganhos do processo de envelhecimento (PECORA; ANJOS; PAREDES, 2010; UCHÔA; FIRMO; LIMA-COSTA, 2002), cada vez mais tem sido propagada uma visão estereotipada da velhice, compreendendo esta como uma busca pautada na ideia de eterna juventude com a negação de questões próprias dessa fase da vida (PINHO, 2008). Entretanto, as alterações biológicas somadas às desigualdades sociais próprias do nosso país têm produzido um processo de envelhecimento marcado por enfermidades e agravos, com um número alto de idosos acometidos por doenças crônicas (VERAS, 2009).

Enquanto a resposta a essas demandas, em termos de efetividade de políticas públicas, se encontra em processo de consolidação/construção, Veras (2009) ressalta que a cada novo ano, 650 mil pessoas avançam para a casa dos 60 anos e que a maior parte delas convive com uma doença crônica. É um quadro que exige, principalmente, uma assistência que atenda às necessidades das pessoas idosas de forma integral em razão da complexidade intrínseca ao processo de adoecimento. Para tanto, é preciso conhecer como se dá a vivência desse processo, justificando uma investigação articulada dos processos de envelhecer e adoecer, sem, contudo, deixar de considerar os ganhos do processo de envelhecer adoecendo, mas também sem deixar de olhar para a realidade cotidiana que associa o envelhecer à perda da saúde e a emersão da doença.

Para atender a tal pleito, utilizamos, enquanto recorte teórico e metodológico, a Teoria das Representações Sociais (TRS), elaborada pelo psicólogo social Serge Moscovici, em 1961, a partir de sua obra denominada La psychanalyse, son image et son publique, na qual ele analisa a apropriação da psicanálise pela sociedade parisiense. 
A escolha da teoria se justifica em decorrência dela não apenas legitimar o estudo do senso comum, mas também enfatizar a importância da comunicação no processo de construção e transformação das representações sociais, e, ainda, assinalar que estas regem as condutas e as interações entre as pessoas. De acordo com Sá (2004), os indivíduos são entendidos como pensadores ativos em interação social contínua e, a partir desse processo, produzem e comunicam representações sociais e soluções para as questões que se apresentam em sua vida. Neste sentido, a sociedade é abordada como um sistema de pensamento socialmente construído.

Jodelet, principal colaboradora de Moscovici, define as representações sociais como "[...] uma forma de conhecimento, socialmente elaborada e partilhada, tendo uma visão prática e concorrendo para a construção de uma realidade comum a um conjunto social" (JODELET, 2001, p. 22). Abordar as representações sociais, neste contexto, requer uma escuta sensível aos sujeitos da pesquisa - idosos acometidos por adoecimento crônico -, visto a legitimação que se busca do saber do senso comum.

A autora descreve o espaço de estudo em representações sociais considerando-o multidimensional. Jodelet propõe um esquema "[...] que caracteriza a representação como uma forma de saber prático ligando um sujeito a um objeto" (JODELET, 2001, p. 21). Sugere, para o estudo dessa díade, três questionamentos: "Quem sabe e de onde sabe?", “O que e como sabe?" e "Sobre o que sabe e com que efeitos?" (JODELET, 2001, p. 28). É na tentativa de responder essas questões que se buscará compreender como os participantes do estudo, idosos hospitalizados no Hospital Universitário Júlio Muller (HUJM) por comprometimentos cardiovasculares, elaboram e compartilham em suas vidas cotidianas o objeto: envelhecer adoecendo. Neste trabalho, as dimensões envelhecimento e adoecimento estão relacionadas devido ao locus escolhido: trata-se de um serviço hospitalar público de alta complexidade que atende exclusivamente pacientes referenciados pelo Sistema Único de Saúde (SUS) e no qual as pessoas encontram-se internadas por algum agravo da doença.

A velhice, como as outras etapas da vida, não representa apenas um fato biológico, mas constitui-se também como categoria social e culturalmente construída (BEAUVOIR, 1970; MINAYO; COIMBRA JR., 2002). Beauvoir, em 1970, aliás, denunciava que os padrões de vida miseráveis impostos pela sociedade aos velhos comprovam a falência de nossa civilização. A filósofa existencialista, ao discorrer sobre a velhice, apontava para "[...] a necessidade de tudo rever, desde o princípio" (BEAUVOIR, 1970, p. 12).

Essa necessidade apontada é cada vez mais atual, visto que, na contemporaneidade, o apelo ao corpo jovem e economicamente ativo e os valores 
relacionados à competitividade e rapidez acabam impelindo os idosos para um lugar de exclusão. A autora sobre este aspecto ressalta: "[...] é a exploração dos trabalhadores, a atomização da sociedade, a miséria de uma cultura apanágio de um mandarinato que levam a essas velhices desumanizadas" (BEAUVOIR, 1970, p. 12).

Mucida (2006) explica o envelhecimento como um processo presente desde o nascimento à morte, enfatizando a importância de se considerá-lo como multifatorial, a partir das dimensões fisiológicas, psicológicas e sociais. Entretanto, observa que o discurso médico, ao tomar o corpo como organismo marcado pelo determinismo biológico, retrata a velhice somente sob o âmbito das perdas e da diminuição da capacidade intelectual, o que pode contribuir para uma visão da velhice entendida como um amontoado de doenças.

Freitas e Ferreira (2013), ao buscarem os elementos centrais que compõem as representações sociais de adolescentes de uma instituição de ensino médio, estadual, da cidade de Fortaleza, CE, sobre a velhice e a pessoa idosa, concluíram que, embora os sujeitos pesquisados relacionem a velhice à experiência adquirida com o correr dos anos, prevalece entre eles a ideia de velhice atrelada a aspectos patológicos como doenças e perdas advindas do declínio físico. De forma semelhante, os familiares de idosos, hospitalizados em uma Casa de Saúde no Rio de Janeiro, expressam, em suas representações acerca da velhice, características negativas que acreditam serem inerentes à pessoa idosa, como perdas da saúde, da beleza e dos amigos (CRUZ; FERREIRA, 2011).

Essa associação do envelhecimento à eclosão de enfermidades está presente também nas representações dos próprios idosos, sejam eles ex-estudantes de uma instituição federal de ensino da cidade do Rio de Janeiro, RJ (SANTOS; TURA; ARRUDA, 2013); residentes da área adscrita da Unidade de Saúde da Família (USF) Passo da Pátria, na cidade de Natal, RN (MENEZES; OLIVEIRA, 2011); ou participantes dos Grupos de Convivência Juventude Prateada e Renascer, localizados na cidade de João Pessoa, PB (ARAÚJO; COUTINHO; CARVALHO, 2005).

Na pesquisa realizada com idosos por Garcia et al. (2005) acerca de como eles entendem seu processo de adoecimento, foi observado os diferentes modos de aceitação das perdas e ganhos do envelhecimento e algumas dificuldades dos sujeitos em lidar com o adoecer, pois este representaria a necessidade de cuidados - o que parece estar associado à perda de autonomia.

Entretanto, na pesquisa realizada por Santos, Tura e Arruda (2013), intitulada As representações sociais de "pessoa velha" construídas por idosos, os sujeitos, em forma de protesto, abordam o tratamento dispensado aos mais velhos como uma segregação realizada pelas pessoas não idosas que, impulsionadas 
por concepções de declínio mental ou físico e de inutilidade, retiram da "pessoa velha" seu papel social. Os autores concluem que os reflexos disso são evidenciados em infraestrutura deficitária para a circulação dos idosos nos espaços públicos e dificuldade na assistência à saúde, bem como outras formas de desrespeito aos seus direitos. Em última instância, o envelhecimento e o adoecimento são percebidos como perda da capacidade de trabalho, o que, em nossa sociedade capitalista, é igualado à inutilidade no sentido de improdutivos (GARCIA et al., 2005; CRUZ; FERREIRA, 2011).

Contudo, mesmo com as restrições impostas pelo quadro de saúde, os familiares e a equipe de saúde podem contribuir para a autonomia das pessoas idosas em relação ao seu tratamento e sua própria vida. Isso pode ser observado na pesquisa com idosas de Bambuí, MG (UCHÔA; FIRMO; LIMA-COSTA, 2002), que avaliam seus problemas de saúde mais pela capacidade de enfrentá-los do que pela doença em si e apontam o apoio familiar e de instituições comunitárias ou religiosas como principal recurso de enfrentamento.

Minayo e Coimbra Jr. (2002) explicam a importância de pensar a velhice também como uma questão pública, o que seria bem diferente de tratá-la como problema social. Dessa forma, o envelhecimento é retirado do âmbito privado e individual para ser visto de forma mais abrangente, inserido na esfera da grande política e das políticas sociais, apontando para a necessidade de atuações mais condizentes com as dessa população. Tal decisão implicaria, principalmente, numa mudança para uma visão holística em relação ao envelhecimento, enquanto positivação da identidade do idoso, que significa:

\section{[...] por um lado, reconhecer o que há de importante e específico nessa etapa da vida para desfrutá-lo; por outro, compreender, do ponto de vista do grupo social, os sofrimentos, as doenças e as limitações com toda a carga pessoal e familiar que tais situações acarretam, embora nunca tratando tais aconteci- mentos dolorosos e tristes como sinônimos de velhice. (MINAYO; COIMBRA JR., 2002, p. 14)}

Levaremos, ainda, em consideração, a proposição de Debert (1999) ${ }^{3}$ apud Uchôa, Firmo e Lima-Costa (2002), de que a velhice não deve ser dissociada da doença e da morte, em contraposição à ideia da eterna juventude como um bem possível de ser alcançado. Sobre isso, argumenta:

[...] não adianta negar, o importante é integrar os recursos disponíveis (individuais e coletivos) em um processo no qual compensação pela

3 DEBERT, Guita Grin. A Reinvenção da Velhice. São Paulo: Edusp, 1999. apud UCHÔA; FIRMO; LIMA-COSTA, 2002. 

aos idosos continuar, mesmo quando têm graves problemas de saúde. (UCHÔA; FIRMO; LIMA-COSTA, 2002, p. 33)

Sendo o ser humano possuidor de uma capacidade de reorganizar sua existência a partir das situações que se apresentam, a velhice e até mesmo a doença se manifestam como momento propulsor de reflexões, de olhar para si mesmo e olhar em volta. Tendo em vista que as políticas públicas não conseguem alcançar plenamente essa população e olhares enviesados e excludentes ainda lhes são destinados pela sociedade, e, ainda, atendendo ao propósito da presente pesquisa de legitimar o saber popular dos pacientes hospitalizados no Hospital Universitário, no contexto cuiabano, perguntamos: quais são as formas encontradas pelas pessoas que envelhecem adoecendo de estar no mundo e de significar sua experiência para continuar vivendo?

\section{Método}

O estudo foi realizado nas Clínicas Médica e Cirúrgica do Hospital Universitário Júlio Muller (HUJM), da Universidade Federal de Mato Grosso (UFMT), na cidade de Cuiabá, estado do Mato Grosso. Os sujeitos, em um total de 15 idosos, eram pessoas que se encontravam hospitalizadas em decorrência de algum comprometimento cardiovascular, durante o período de setembro a outubro de 2012. Todos os participantes encontravam-se em condições de responder às questões e aceitaram compartilhar suas histórias de vida.

A coleta de dados foi realizada através de entrevistas semiestruturadas com base em um roteiro previamente elaborado, tendo sido solicitado que as pessoas falassem a respeito de: sua vida, família, profissão e saúde; o significado de envelhecer adoecendo; as dificuldades e mecanismos de enfrentamento desse processo; e o que poderiam ter feito para envelhecer com mais saúde. Buscou-se também investigar os aprendizados obtidos, as vivências, as experiências acumuladas, os projetos, os sonhos e os desejos dos idosos.

Para a garantia da fidedignidade dos dados, estes foram registrados por meio de gravação em áudio e mediante assinatura do Termo de Consentimento Livre e Esclarecido. Foi aplicado, ainda, um questionário socioeconômico para caracterização dos sujeitos.

A pesquisa foi submetida à Plataforma Brasil e obteve aprovação do Comitê de Ética em Pesquisa do Hospital Universitário Júlio Muller, com o seguinte número do Certificado de Apresentação para Apreciação Ética (CAAE): n 07120512.1.0000.5163. A mesma foi efetivada conforme as diretrizes 
estabelecidas pela resolução n ${ }^{\circ}$ 196/1996 do Conselho Nacional de Saúde (CNS) que versa sobre a pesquisa envolvendo seres humanos (BRASIL, 1996).

O material discursivo foi organizado em um banco de dados preparado para ser processado pelo software ALCESTE (Análise Lexical por Contexto de um Conjunto de Segmentos de Texto). Trata-se de um programa criado na França por Max Reinert no Centro Nacional Francês de Pesquisa Científica (CNRS, em francês) e introduzido no Brasil a partir de 1998. Esse programa de análise de dados agrupa o corpus textual em classes, apontando a informação principal de um texto e, mediante uma análise de classificação descendente, realiza análise lexical quantitativa considerando a palavra como unidade e também oferece a sua contextualização no corpus ou entrevista (CAMARGO, 2005). O aproveitamento desse material discursivo, no presente estudo, foi de $75 \%$ do corpus de análise.

\section{Participantes}

Os 15 idosos participantes do estudo representaram 27,8\% dos idosos hospitalizados no período de setembro a outubro de 2012 no HUJM. Desse total de idosos entrevistados, oito eram do sexo masculino e sete do sexo feminino, com a faixa etária compreendida entre 61 e 79 anos. Quanto ao estado civil, oito eram casados, um solteiro, dois divorciados e quatro viúvos. Em relação ao nível de escolaridade, três eram analfabetos, nove possuíam o nível fundamental incompleto, um o fundamental completo e dois cursaram nível médio completo - nenhum idoso possuía nível superior. Quanto à proveniência, sete residiam na capital, Cuiabá, quatro em uma cidade vizinha, em Várzea Grande, três vieram de outros municípios do Mato Grosso e um do estado de Rondônia.

Quanto à atividade econômica realizada, quatro entrevistados declararam não serem aposentados, exercendo ainda suas atividades laborais, 10 informaram serem aposentados e um deles declarou não trabalhar nem ser aposentado. Em relação à renda, três possuem renda familiar de até um salário mínimo, cinco possuem de um a dois salários mínimos, e sete de dois a três salários mínimos. Quanto aos hábitos de vida, apenas um idoso declarou ser fumante, e três disseram ter parado de fumar; 11 não ingerem bebidas alcoólicas, um declarou ingerir bebida alcoólica raramente e três disseram ter parado de beber. Quanto à atividade física, 10 não realizam, enquanto os outros cinco disseram realizar atividades ao menos duas vezes por semana.

Em relação à hospitalização, dois entrevistados estavam em sua primeira internação e os outros 13 já foram hospitalizados pelo menos uma vez no ano de 2012 e pelo menos três vezes nos últimos 10 anos. 
No presente estudo, todo o discurso dos sujeitos foi agrupado em um corpus que denominamos envelhecer adoecendo, o próprio objeto de investigação, e foi composto por 15 unidades de contexto inicial (UCI) ou entrevistas. A figura 1 apresenta o dendrograma da Classificação Hierárquica Descendente (CHD), com as quatro classes agrupadas pelo software ALCESTE, e, ainda, as palavras mais representativas de cada Classe, extraídas de uma longa lista fornecida pelo programa e ordenadas de forma decrescente, tendo como referência o Qui quadrado $\left(\chi^{2}\right)$, ou seja, as palavras que obtiveram maior associação com a Classe.

As Classes foram nomeadas de acordo com a análise do conteúdo do material discursivo produzido pelos sujeitos. São elas: Classe 1: Vivências de adoecimento e seu enfrentamento; Classe 2: História de vida e sua interface com o processo de adoecimento, que compõe o bloco de agrupamentos denominado de Narrativas da vida diária; Classe 3: O cuidado do idoso doente e suas implicações; e Classe 4: A hospitalização e a sua rotina, que compõe a outra ramificação do dendrograma nomeada de Narrativas do cotidiano hospitalar, conforme pode ser observado recorrendo-se à figura abaixo.

Figura 1 - Classificação Hierárquica Descendente - Dendrograma de classes estáveis geradas pelo software. ALCESTE ( $N=15)$

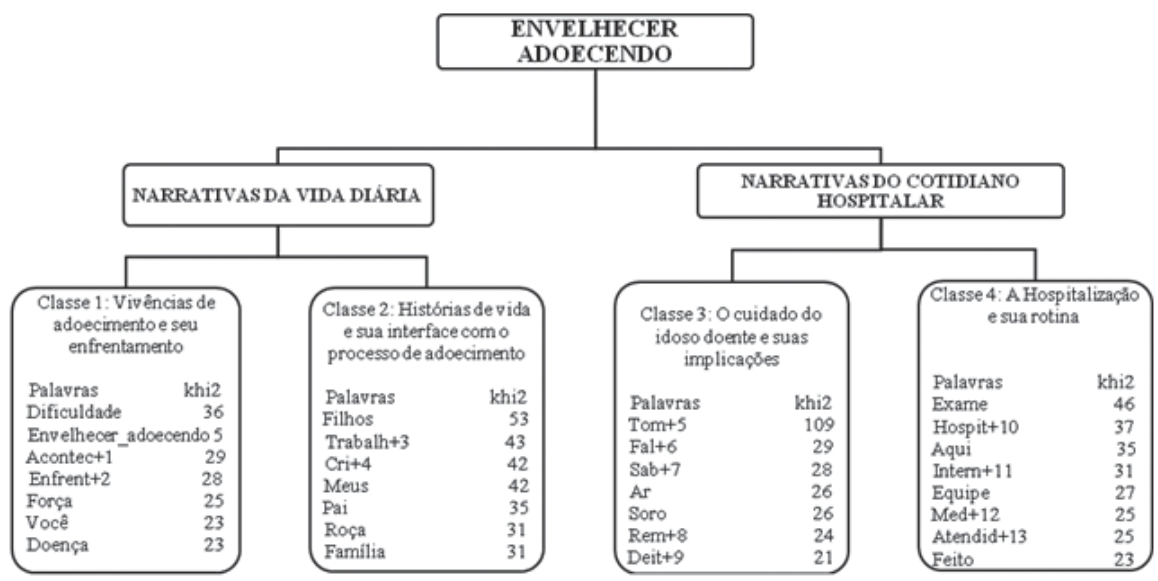

Legenda:

+1 - Aconteça, acontece, acontecem, acontecer, aconteceu.

+2 - Enfrentando, enfrentar, enfrento.

+3 - Trabalha, trabalhamos, trabalhar, trabalhava. 
+4 - Cria, criada, criado, criamos, criar, criei, criou.

+5 - Toma, tomando, tomar, tomaram, tomava, tomei, tomo.

+6 - Fala, falam, falando, falar, falaram, falava, falei, falo, falou.

+7 - Sabe, sabemos, saber, sabia, sabiam.

+8 - Remedinho, remédio, remédios.

+9 - Deitar, deitei.

+10 - Hospitais, hospital.

+11 - Internação, internada, internado, internar, internaram, internei.

+12 - Média, médica, médico, médicos, medir.

+13 - Atendida, atendido.

\subsection{Classe 1: Vivências de adoecimento \\ e seu enfrentamento}

Esta classe constitui-se do discurso das dificuldades relativas ao envelhecer adoecendo, apresentando de forma bastante positiva a mobilização interna para o enfrentamento da situação vivenciada. A Classe 1 é composta por 126 unidades de contexto elementar (UCE), segmentos de textos, correspondendo a $28 \%$ do total do material discursivo aproveitado.

Santos e Sebastiani (2003) ressaltam o aparecimento de uma doença como algo a ser combatido, por isso a necessidade manifesta a ingestão de medicamentos e de recorrência aos profissionais de saúde. No entanto, alertam os autores: "[...] muitas vezes parece que se esquece o significado do adoecer, cuidando apenas do órgão prejudicado, dividindo o indivíduo entre corpo e mente, esquecendo-se da história pregressa pessoal, familiar e social" (SANTOS; SEBASTIANI, 2003, p. 151). Quando questionados acerca de envelhecer adoecendo, os entrevistados realizaram uma reflexão sobre a própria vida, abordando o que pode ter contribuído para o processo de adoecimento, conforme explicita um dos entrevistados no depoimento seguinte:

Conforme a idade vai chegando, todas aquelas coisas de quando éramos novos vão se acumulando, vamos envelhecer adoecendo. Eu estava pensando que seja isso porque se desde novo tivéssemos experiência e fôssemos cuidando, nós envelheceríamos, mas não adoeceríamos, porque não teria como adoecer, acredito que seja isso. (Senhora de 61 anos)

Essa elaboração positiva acerca da própria vida, proporcionada também pelo próprio processo de adoecimento somado à hospitalização, permite redefinir prioridades, conforme aponta outro participante da pesquisa:

E olhando isso, hoje eu penso que a partir de agora eu vou cuidar melhor da minha vida e da minha família. Vou fazer um projeto para não precisar mais estar se desgastando tanto e abusando tanto das circunstâncias para ficar doente. (Senhor de 63 anos) 
Foram inúmeras as dificuldades apontadas pelos entrevistados acerca de envelhecer adoecendo, entretanto, os recursos individuais somados ao suporte social permitem o enfrentamento de tal situação. Nesta Classe, ainda pudemos reconhecer uma dimensão espiritualista em relação à vida, uma fé que não engloba apenas questões religiosas, mas uma fé nas pessoas, conforme expressa o depoimento seguinte:

Dessas experiências de adoecimento, o que eu nunca esqueço são os bons tempos que deixamos para trás. E também a boa vontade, porque tem muita gente para colaborar com o idoso. Então isso nos deixa bem mais feliz, nos dá mais motivos para viver. Isso é gratificante, ficamos preenchidos de força com uma boa palavra, uma amizade, um sorriso, um aperto de mão, são coisas que acontecem. (Senhor de 65 anos)

A partir do conteúdo discursivo, é possível observar que o adoecimento com as limitações impostas são entendidas como mais uma situação a ser enfrentada dentre tantas que os entrevistados já passaram. Por terem vivenciado tais situações e pelo próprio avançar da idade, eles adquiriram experiência:

E aí a vida é essa, não é? Você vai fazer o quê? As dificuldades são normais, para tudo tem que ter paciência. Tem que ter paciência e ir em frente, fazer aquilo que é melhor, porque não existe problema sem solução, agora você tem que ver como você vai resolvê-lo, isso é uma, é muito certo. (Senhor de 74 anos)

Apesar dessa experiência, algumas falas, como a seguinte, corroboram com a ideia de que o que torna a velhice "sinônimo de sofrimento é mais o abandono que a doença em si, é mais a solidão que a dependência" (MINAYO; COIMBRA JR., 2002, p. 14):

Porém eu sempre digo, falo sempre e vou continuar falando, o mais difícil não é só a doença, o mais difícil é você adoecer - e não é só na minha idade - o mais difícil é adoecer e não ter um agasalho. O quê é agasalho? Não é sentir frio, colocar um cobertor ou um paletó. O agasalho é você ter alguém para ficar do seu lado, para cuidar. (Senhor de 65 anos)

A equipe de saúde que está ali dia a dia com o usuário pode contribuir muito no enfrentamento das questões que permeiam o processo de envelhecer adoecendo. Para isso, deve estar sensível e ter uma visão holística sobre esse processo. Neste sentido, destacamos o papel do psicólogo em sua função de interlocutor entre o paciente e a equipe, além de inserir a dimensão da escuta no cuidado em saúde na medida em que viabiliza um espaço para a expressão 
das dores emocionais do paciente e de sua família, tal como compartilhado por uma das senhoras:

Porque o amor e o carinho estão sob todas as coisas. Quando você tem carinho pelos outros, você sabe conversar, mesmo se a pessoa estiver revoltada, você vai e conversa com ela, bem mansinho, ela vai indo e relaxa, ela entende. (Senhora de 65 anos)

\subsection{Classe 2: História de vida e sua interface com o processo de adoecimento}

A Classe 2 constitui-se de 128 unidades de contexto elementar, representando $29 \%$ do total do material considerado para análise, e possui conteúdo bastante significativo por englobar as histórias de vida desses idosos, as condições a que estiveram sujeitos e influência destas no processo de adoecimento. A família, nesta classe, além de se relacionar diretamente com sua constituição enquanto pessoa, representa o que conseguiram construir durante suas vidas, sendo, ainda, seu suporte.

A partir do relato de suas histórias de vida e também com base no questionário socioeconômico realizado, fica evidente que os entrevistados, em sua maioria, tiveram uma infância e adolescência vividas em condições precárias e sem muitas perspectivas, conforme explicitado por um dos participantes do estudo:

Eu já trabalhei muito na roça. Eu trabalhava, primeiro ajudava meu pai na roça, plantava verdura, depois eu casei e continuei ajudando meu marido na roça plantando verdura também. (Senhora de 79 anos)

Muitos dos entrevistados foram criados em sítios e, desde pequenos, trabalhavam na roça. Alguns permaneceram na zona rural e lá criaram seus filhos, como é o caso da senhora citada no depoimento acima e que até hoje vive fora da cidade. Outros saíram do sítio e foram para a cidade em busca de emprego ou dos serviços básicos como educação e saúde, bastante precários na zona rural. Sem outras probabilidades, desde cedo o trabalho era a saída na luta pela sobrevivência - trabalho este pesado, excessivo, e que pode ter influenciado no processo de adoecimento, conforme explicitam:

A minha profissão foi grande desde que cheguei aqui nesse Mato Grosso. Se bem que lá na Bahia estávamos trabalhando como jumentos. Era tudo difícil 
para nós, comecei a criar os filhos, mas não tinha escola para colocar os filhos. Fomos pelejando até que a menina completou quatro anos e nós viemos para cá. (Senhora de 74 anos)

Eu fui um rapaz que foi criado sem pai, eu já fui chefe de família desde os 14 anos [...] quando eu fui pensar em alguma coisa para mim já estava velho, aí casei, veio família e eu trabalhava na lavoura. Depois que apareceram umas oportunidades de emprego. Eu cheguei a trabalhar em São Paulo e pensava no futuro, mas quando eu estava começando a trabalhar, trabalhei 12 anos, entrou um problema de saúde, em decorrência do trabalho. (Senhor de 77 anos)

Com a aposentadoria há perdas de ordem econômico-social, o que é apontado por alguns autores como causador de constrangimento e ainda agravado quando se tem uma doença crônica e as necessidades correspondentes (PINHO, 2008). Além disso, apesar de ter sido abordada a perda da capacidade de trabalho, fica evidente a lamentação pelo trabalho excessivo de uma vida inteira que custou a saúde e pela carência do retorno esperado em termos de conforto na velhice. Vejamos o que diz um dos idosos:

Minha mãe viúva criou a família sem marido e viemos para cá crianças. Hoje sou casado, tenho seis filhos, cinco casados e um solteiro que mora comigo. Mas a situação financeira é como dizem: a luta é para sempre. E eu cheguei ao ponto em que fiquei na idade e o salário não dá pra gente sobreviver como precisa viver. (Senhor de 77 anos)

É importante ressaltar que mesmo em condições socioeconômicas desfavoráveis, os entrevistados abordam as conquistas alcançadas no decorrer da vida. Neste sentido, ter uma família, ter filhos e poder proporcionar a eles algo que os idosos não tiveram como o estudo e a tão sonhada casa própria, são apontadas como as vitórias alcançadas em meio a tantas dificuldades. É essa família que, na maioria dos casos, constitui o suporte necessário no momento do adoecimento, malgrado os idosos identificarem que o cuidado que eles precisam causam certos transtornos e dificuldades para os familiares, conforme confessam:

Arrumei família e acabei criando os meus filhos, mas eu coloquei todos os meus filhos na escola. [...] mesmo assim, eu consegui segurar aos pouquinhos e hoje tenho minha casa, eu tenho minha família, tenho os meus filhos, tenho as minhas filhas e o que eu pude fazer por eles eu fiz. Hoje eu me encontro com 77 anos, doente assim desse jeito e não é fácil. (Senhor de 77 anos) 
Então, eu sei que é difícil para ela também, mas o que ela está fazendo por mim Deus vai dar a recompensa para ela. A união da família faz tudo, ajuda a passar por essa situação, porque não é fácil. (Senhora de 62 anos)

\subsection{Classe 3: O cuidado do idoso doente e suas implicações}

A terceira classe representa $19 \%$ do total das unidades de contexto elementar (87 UCE) das 15 entrevistas, e apresenta relação direta com a Classe 4, que trata de questões da rotina hospitalar. Foram apreendidos por aquela classe, principalmente, conteúdos referentes ao cuidado do idoso pelos familiares e pela equipe, o cuidado consigo mesmo e na cooperação com a equipe e até mesmo o cuidado que não foi realizado com o devido respeito.

Para Fukumitsu (2010), a impossibilidade de remissão dos sintomas e da eliminação total da doença é extremamente angustiante, daí a necessidade de acolher aquilo que é trazido pelo usuário e que pode ter seu alívio no cuidado a na possibilidade de estar com o outro. Vejamos em que medida os apontamentos da autora casa com a solicitação dos entrevistados, mediante o depoimento que segue:

Não que eu fique falando da dor o tempo todo, mas eu sinto, eu suporto, mas sinto que tem uma dor comigo. Sinto que cada dia que passa eu estou morrendo aos pouquinhos. (Senhor de 62 anos)

A autora aborda, assim, a necessidade dos profissionais de saúde se colocarem em um encontro com o outro, um contato profundo para que haja a percepção de suas reais necessidades, que de forma alguma são apenas orgânicas (FUKUMITSU, 2010). São comuns nos serviços de saúde os profissionais não compreenderem o usuário e, ainda, não se fazerem compreender ao utilizar termos técnicos ou resumidos. Essa falha na comunicação contribui para o fracasso do tratamento e para o retorno deste usuário no serviço ou a outros serviços na rede, daí a importância de uma comunicação efetiva e satisfatória entre equipe e usuário, questão trazida pelos entrevistados em seus relatos e que pode redirecionar o autocuidado, tal como declara uma das pessoas:

Então nós vamos embora sabendo como tomar o remédio [...], eu não sabia a importância de tomar remédio ou até mesmo de tomar um chá, de cuidar da alimentação. Eu pensava: "Vou tomar um remédio pra que se sinto falta de ar?" (Senhor de 62 anos) 
Muitos dos participantes da pesquisa já passaram por diversos serviços de saúde no interior e na cidade sem que tivessem sido adequadamente orientados ou encaminhados. Em situações mais graves, fica evidenciado o desrespeito sofrido pelo idoso, como é o caso de uma senhora moradora da zona rural, no interior do estado, que chegou ao hospital com uma doença em estado avançado e não diagnosticada, apesar dos seus esforços e da família na busca pelos serviço de saúde nas cidades vizinhas. Ela relata emocionada a precariedade do atendimento oferecido:

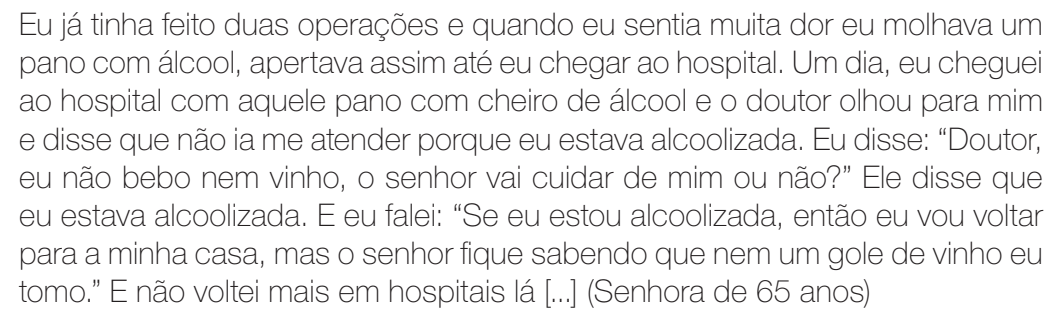

Outra dimensão é o cuidado recebido pelos seus familiares, principalmente do cônjuge, e que concorda com o já abordado nas outras classes, o fato da família constituir o suporte de apoio e influenciar positivamente no enfrentamento das dificuldades de envelhecer adoecendo, corroborando, com isto, o depoimento pertencente à Classe 3 a seguir apresentado:

Não é fácil, mas é enfrentado com o apoio dela. E com coragem porque eu penso que se eu fosse sozinho, eu não teria como sobreviver. Muitas vezes ela sai comigo meia-noite para a policlínica, às vezes já aconteceu de irmos ao começo da noite e voltar de madrugada. Nós íamos embora, mas daí eu não aguentava e voltava novamente para lá. E quem quer saber disso? Você estar dormindo tranquilo e ter que levantar duas ou três vezes na noite para levar alguém à policlínica, isso não existe! (Senhor de 62 anos)

\subsection{Classe 4: A hospitalização e a sua rotina}

Por fim, a última classe da análise hierárquica aqui utilizada envolve $24 \%$ do total do material verbal utilizado, completando 111 unidades de contexto elementar e ressaltando questões em torno da realidade hospitalar.

O material discursivo permite inferir que a hospitalização na instituição de saúde pesquisada vai ao encontro das expectativas dos usuários, visto que o serviço é elogiado pelos mesmos. Entretanto é percebido que esse 
enaltecimento decorre dos transtornos e obstáculos na busca por assistência e, ainda, de experiências desagradáveis vivenciadas em outras instituições de saúde, conforme depoimento dos usuários dos serviços:

Minha internação foi até com rapidez, acho que não demorou muito, porque eu vejo pessoas que vão para o pronto-socorro e esperam tanto tempo por uma consulta ou ficam lá por uns meses esperando por uma cirurgia. (Senhor de 65 anos)

Mandavam para um lugar, depois mandavam para outro até que cheguei ao pronto-socorro e, de lá, me mandaram para cá. Eu sei que é difícil ser pobre e não ter recursos para procurar um médico e ter que precisar dos médicos do SUS. (Senhora de 61 anos)

É importante destacar que a maioria dos usuários idosos entrevistados conseguiu distinguir o trabalho de cada profissional dentro da equipe e, ainda, o trabalho enaltecido, segundo apontam, é pautado na confiança estabelecida entre usuário e equipe. Vejamos o que declaram:

A equipe é muito boa, é muito boa, fui bem atendido por todo mundo. Eu acho que estão fazendo o suficiente porque eu não tenho nada a reclamar. (Senhor de 77 anos)

Esta é a terceira vez que eu interno aqui no Júlio Muller. É um hospital que eu confio muito, as pessoas aqui me tratam bem, já fui até operado aqui. (Senhor de 76 anos)

$\mathrm{O}$ apoio recebido tanto pelos familiares como pela equipe permite que os percalços da rotina hospitalar sejam minimizados. Assim, as modificações exigidas pelo processo de adoecimento e de hospitalização balizam-se no encontro com o outro, peça fundamental na manutenção da vida, conforme aponta um dos senhores atendidos na instituição:

Nós temos o apoio de muita gente, são nossos amigos, eles ligam para cá, telefonam todos os dias, mandam mensagens, e eu fico feliz, contente [...] Há uns 15 dias atrás, meu pai e minha mãe, que estão com quase 90 anos, vieram lá de Rondônia só para me visitar [...] A visita deles foi maravilhosa, isso dá ânimo para o paciente se restabelecer logo. (Senhor de 63 anos) 
Levando em consideração que o espaço de estudo em representações sociais é multidimensional (JODELET, 2001), as conclusões aqui apresentadas atenderão a proposta de Jodelet (2001, p. 21) e os questionamentos por ela realizados. "Quem sabe e de onde sabe?" Esta pergunta levou-nos à definição dos sujeitos e seu contexto. A população investigada foi idosa com comprometimentos cardiovasculares, pertencente a uma classe socioeconômica pouco favorecida e no contexto de internação de um hospital universitário de atendimento exclusivo do SUS, na cidade de Cuiabá, Mato Grosso.

"O que e como sabe?" levou os participantes do estudo a discutirem o envelhecimento atravessado pelo adoecimento, apresentando suas perdas e dificuldades relativas, mas apontando de forma positiva para o que constitui seu mecanismo de enfrentamento. Este perpassa pela força interior alcançada pelas experiências vivenciadas, pelo apoio familiar, pelo cuidado recebido e o acesso aos serviços de saúde.

"Sobre o que sabe e com que efeitos?", permite a consideração de que a representação social de envelhecer adoecendo é concebida a partir de quatro dimensões, a saber: adoecimento (Classe 1), história de vida (Classe 2), cuidado (Classe 3), e hospitalização (Classe 4); que se cruzam e se complementam, formando uma rede de significados para a representação social investigada.

A ancoragem ${ }^{4}$ da representação de envelhecer adoecendo, a partir das dimensões mencionadas, se dá por meio do curso de vida difícil e sofrido, pelas histórias e escolhas realizadas, especialmente notadas pelas más condições de trabalho, hábitos de vida pouco saudáveis, descuido e despreocupação com a saúde, implicando em baixa procura e dificuldade de acesso ao sistema de saúde.

A representação, ainda, é ancorada no curso de vida natural, cujo adoecimento é tido, pelos participantes do estudo, como consequência do processo de envelhecimento. Concluímos que, ao representarem o envelhecer adoecendo como um processo natural da vida, uma das consequências disso implica na pouca clareza da obrigação do Estado na garantia pela saúde. Neste aspecto, o cuidado, quando prestado de forma efetiva, é sentido como caridade e não como direito.

Outra consequência notada, visto que as representações sociais são guias para as ações (ABRIC, 2001; JODELET, 2001), tendo levado Abric (2001, p. 156) a considerar que "[...] os comportamentos dos sujeitos ou dos grupos não são

4 As representações sociais, no entender de Moscovici (1978), são elaboradas com base em dois processos: a objetivação e a amarração ou ancoragem. A ancoragem tem a função de incorporar o novo, interpretar e dar significado à realidade, assim como orientar os comportamentos e as relações sociais (MOSCOVICl, 1978; JODELET, 2001). 
determinados pelas características objetivas da situação, mas pela representação desta situação", se relaciona ao autocuidado escasso em relação à saúde e qualidade de vida, tendo em vista que o envelhecer adoecendo é naturalizado pelos sujeitos e a doença já é esperada no curso de vida.

A doença, aliás, neste cenário, é a objetivação ${ }^{5}$ da representação social investigada, justificada e ancorada nas difíceis condições de vida a que estiveram sujeitos. Ela, doença, aliás, desperta para a necessidade de cuidado, quer do outro - família ou profissional de saúde - e de si, mediante autocuidado.

Envelhecer adoecendo, assim, é um processo construído ao longo da vida, que explicita perdas, em que a mais notada dela é a perda da saúde pela eclosão da doença, conforme também se evidenciou nos estudos de Uchôa, Firmo e Lima-Costa (2002); Pecora, Anjos e Paredes (2010); e Santos, Tura e Arruda (2013).

Esses estudos, ainda, apontam ganhos, também evidenciados nas representações que os idosos compartilharam na presente pesquisa. Os proveitos são notados no enfrentamento da doença, no autocuidado que passam a desenvolver quando a enfermidade é explicitada, e também no confronto com a visão natural do envelhecer adoecendo que adotaram ao longo de suas trajetórias, podendo, no momento presente, questionarem e lamentarem por não terem se cuidado.

Esta primeira aproximação com o tema em nossa realidade local permite-nos refletir acerca da fragilidade dos idosos quanto aos seus direitos e ao acesso à saúde, mas também em relação ao autocuidado ao longo da vida. Isso implica em maior atenção e cuidado da equipe de saúde na manutenção de seus direitos e incentivo à autonomia, ainda que atentos às limitações dessa fase da vida. É desejável que esta investigação impulsione discussões acerca do atendimento integral ao idoso levando-se em consideração seus aspectos psicossociais.

5 A Objetivação, um dos processos formadores da representação social, segundo Moscovici (1978), consiste em transformar uma idéia ou conceito, que é da ordem do abstrato, em algo concreto, em uma imagem. 

CUIABÁ, MT, BRAZIL

\section{abstract}

This study analyzes the social representations of elderly people hospitalized at University Hospital Júlio Muller, Cuiabá-MT, concerning the aging in sickness process. For this action, interviews were performed and semi-structured with 15 of the elderly hospitalized due to heart problems population. This document was processed by ALCESTE software. The analysis of the subjects allowed the researchers to verify that the representations shared in the project include losses and difficulties related to this sick aging process, but also on a positive side, the whole mechanism of coping and dealing with this situation. And finally, considerations on this mechanism built on the basis of an interior force generated by living though the whole life experience, family support, the care taken and access to health services.

keywords

Aging in Sickness. Elderly Patients. Psychology of Health. Social Representations.

referências

ABRIC, Jean-Claude. O estudo experimental das representações sociais. In: JODELET, Denise (Org.). As representações sociais. Rio de Janeiro: EdUERJ, 2001. p. 155-171.

ARAÚJO, Ludgleydson Fernandes de; COUTINHO, Maria da Penha de Lima; CARVALHO, Virgínia Ângela Menezes de Lucena e. Representações sociais da velhice entre idosos que participam de grupos de convivência. Psicolologia: Ciência e Profissão, Brasília, v. 25, n. 1, p. 118-131, mar. 2005. Disponível em: <http://www.scielo.br/scielo.php?script=sci_ arttext\&pid=S1414-98932005000100010\&lng=en\&nrm=iso>. Acesso em: 18 ago. 2014.

BEAUVOIR, Simone de. A Velhice. São Paulo: Difusão Europeia do Livro, 1970.

BRASIL. Conselho Nacional de Saúde. Resolução n 196 de 10 de outubro de 1996. Aprova as diretrizes e normas regulamentadoras de pesquisas envolvendo seres humanos. Diário Oficial da União, Brasília, DF, out. 1996. Disponível em: <http://www. conselho.saude.gov.br/resolucoes/reso_96.htm>. Acesso em: 25 mar. 2012.

CAMARGO, Brígido Vizeu. ALCESTE: Um programa informático de análise quantitativa de dados textuais. In: MOREIRA, Antonia Silva Paredes (Org.). Perspectivas teórico-metodológicas em Representações Sociais. João Pessoa: UFPB/Editora Universitária, 2005. p. 511-539.

CRUZ, Rosana Cancelo da; FERREIRA, Márcia de Assunção. Um certo jeito de ser velho: representações sociais da velhice por familiares de idosos. Texto \& Contexto Enfermagem, Florianópolis, v. 20, n. 1, p. 144-151, jan./mar. 2011. Disponível em: <http:// 
www.scielo.br/scielo.php?script=sci_arttext\&pid=S0104-07072011000100017\&lng=e n\&nrm=iso>. Acesso em: 17 jun. 2014.

FREITAS, Maria Célia; FERREIRA, Maria Assunção. Old age and elderly people: social representations of adolescent students. Revista Latino-Americana de Enfermagem, Ribeirão Preto, v. 21, n. 3, p. 750-757, jun. 2013. Disponível em: <http://www.scielo. $\mathrm{br} /$ scielo.php?script=sci_arttext\&pid=S0104-11692013000300750\&lng=en\&nrm=iso >. Acesso em 30 maio 2014.

FUKUMITSU, Karina OKajima. Dilemas do profissional da saúde: considerações sobre angústia e cuidado. In: RIBEIRO, Ana Lúcia Alves; GAGLIANI, Mayra Luciana (Org.). Psicologia e cardiologia: um desafio que deu certo. São Paulo: Atheneu, 2010. p. 191-199.

GARCIA, Maria Alice Amorim et al. Idosos em cena: falas do adoecer. Interface Comunicação, Saúde, Educação, Botucatu, v. 9, n. 18, p. 537-552, set./dez. 2005. Disponível em: <http://www.scielo.br/scielo.php?script=sci_arttext\&pid=S1414-32832005000300006\&lng=en\&nrm=iso>. Acesso em: 15 jan. 2012.

JODELET, Denise. Representações Sociais: um domínio em expansão. In: JODELET, Denise (Org.). As Representações Sociais. Rio de Janeiro: EdUERJ, 2001, p.17-44.

MINAYO, Maria Cecília de Souza; COIMBRA Jr., Carlos Everaldo Alvares (Org.). Antropologia, Saúde e Envelhecimento. Rio de Janeiro: Editora Fiocruz, 2002.

MOSCOVICl, Serge. A representação social da psicanálise. Rio de Janeiro: Zahar Editores, 1978.

MUCIDA, Ângela. O sujeito não envelhece: psicanálise e velhice. 2. ed. Belo Horizonte: Autêntica, 2006.

PECORA, Ana Rafaela; ANJOS, Paula Martins; PAREDES, Eugênia Coelho. O enveIhecimento como processo social. Revista de Educação Pública, Cuiabá, v. 19, n. 39, p. 55-73, jan./abr. 2010.

$\mathrm{PINHO}$, Miriam Ximenes. A velhice em uma visão geriátrica e gerontológica. In: ALMEIDA, Cristiane Palloti; RIBEIRO, Ana Lúcia Alves (Org.). Psicologia em cardiologia: novas tendências. Campinas: Editora Alínea, 2008. p. 177-198.

SÁ, Celso de. Representações Sociais: o conceito e o estado atual da teoria. In: SPINK, Mary Jane (Org.). O conhecimento no cotidiano. São Paulo: Brasiliense, 2004. p. 19-45.

SANTOS, Claudia Tavares dos; SEBASTIANI, Ricardo Werner. Acompanhamento psicológico à pessoa portadora de doença crônica. In: ANGERAMI-CAMOM, Valdemar (Org.). E a psicologia entrou no hospital. São Paulo: Pioneira Thomson Learning, 2003. p. 147-176.

SANTOS, Verônica Braga dos; TURA, Luiz Fernando Rangel; ARRUDA, Angela Maria Silva. As representações sociais de "pessoa velha" construídas por idosos. Saúde e Sociedade, São Paulo, v. 22, n. 1, p. 138-147, jan./mar. 2013. Disponível em: <http:// www.scielo.br/scielo.php?script=sci_arttext\&pid=S0104-12902013000100013>. Acesso em: 17 jun. 2014.

UCHÔA, Elizabeth; FIRMO, Josélia Oliveira Araújo; LIMA-COSTA, Maria Fernanda Furtado. Envelhecimento e Saúde: experiência e construção cultural. In: MINAYO, Maria Cecília de Souza; COIMBRA Jr., Carlos E. A. (Org.). Antropologia, Saúde e Envelhecimento. Rio de Janeiro: Editora Fiocruz, 2002. p. 25-35.

VERAS, Renato. Envelhecimento populacional contemporâneo: demandas, desafios e inovações. Revista de Saúde Pública, São Paulo, v. 43, n. 3, p. 548-554, jun. 2009. Disponível em: <http://www.scielo.br/scielo.php?script=sci_arttext\&pid=S0034-89102009000300020\&lng=en\&nrm=iso>. Acesso em: 2 maio 2012. 
